\title{
Jahrbuch für Soziologiegeschichte 1991
}




\section{Jahrbuch für Soziologiegeschichte 1991}

Herausgegeben von

Carsten Klingemann

Michael Neumann

Karl-Siegbert Rehberg

Ilja Srubar

Erhard Stölting

Leske + Budrich, Opladen 1992 
Herausgeber:

Carsten Klingemann

Michael Neumann

Karl-Siegbert Rehberg

Ilja Srubar

Erhard Stölting

\section{Redaktion:}

Dr. Michael Neumann, Soziologisches Seminar der Universität Göttingen, Platz der Göttinger Sieben 3, 3400 Göttingen.

\section{Beirat:}

David Frisby (Glasgow), Hans Joas (Erlangen), Dirk Käsler (Hamburg), Horst Kern (Göttingen), M. Rainer Lepsius (Heidelberg), Carlo Mongardini (Rom), Paul Neurath (Wien), Sven Papcke (Münster), Michael Pollak (Paris), Otthein Rammstedt (Bielefeld), Günther Roth (New York), Kurt H. Wolff (Newton, Mass.)

\section{Manuskripte:}

Für Interessenten verschickt die Redaktion auf Anfrage ein Merkblatt zur Abfassung von Manuskripten.

ISBN 978-3-8100-0950-0

DOI 10.1007/978-3-322-99643-5

(C) 1992 by Leske + Budrich, Opladen.

Das Werk einschließlich aller seiner Teile ist urheberrechtlich geschützt. Jede Verwertung außerhalb der engen Grenzen des Urheberrechtsgesetzes ist ohne Zustimmung des Verlags unzulässig und strafbar. Das gilt insbesondere für Vervielfältigungen, Übersetzungen, Mikroverfilmungen und die Einspeicherung und Verarbeitung in elektronischen Systemen.

Satz: Leske + Budrich 


\section{Inhalt}

Abteilung I: Hauptartikel

Kurt $H$. Wolff

Von Nichts zu Soziologie

Theresa Wobbe

Mathilde Vaerting (1884 - 1977). Eine Intellektuelle im

Koordinatensystem dieses Jahrhunderts

Ute Michel

Wilhelm Emil Mühlmann (1904 - 1988) - ein deutscher Professor.

Amnesie und Amnestie: Zum Verhältnis von Ethnologie und Politik im

Nationalsozialismus

Hans-Joachim Dahms

Der Positivismusstreit (Fortsetzung)

Abteilung II: Diskussion und Berichte

Erhard R. Wiehn

$\mathrm{Zu}$ Martin Bubers Sammlung ,Die Gesellschaft'. Ein fast

vergessenes Stück Soziologiegeschichte

Filippo Barbano

Die Soziologie in Italien 1945-1989 ............................... 209

Sven Papcke

Die braune Versuchung. Peter Druckers Deutung des Totalitarismus ... 233 Markus Mosen

Angewandte Ethnologie im Nationalsozialismus: Hans Findeisen und sein Eurasien-Institut

Abteilung III: Archiv

Das Paul-F.-Lazarsfeld-Archiv

Die Arbeitsbibliothek von Alfred Schütz in Konstanz

Rassenideologie, Nationalsozialismus und Wissenschaft: Hans F.K.

Günther im Urteil von Wilhelm Emil Mühlmann

$\mathrm{Zu}$ den Autorinnen und Autoren 